\title{
DNA looping between sites for transcriptional activation: self-association of DNA-bound Sp1
}

\author{
Wen Su, ${ }^{1}$ Stephen Jackson,, ${ }^{1,3}$ Robert Tjian,, ${ }^{1,2}$ and Harrison Echols ${ }^{1}$ \\ ${ }^{1}$ Division of Biochemistry and Molecular Biology, ${ }^{2}$ Howard Hughes Medical Institute, University of California, Berkeley, \\ California 94720 USA
}

\begin{abstract}
The Sp1 protein activates transcription from many eukaryotic promoters. Sp1 can act in vivo from enhancer sites that are distal to the promoter and exhibit synergistic interaction with promoter-proximal binding sites. To investigate possible protein-protein interactions between DNA-bound Sp1 molecules, we have used electron microscopy to visualize the DNA-protein complexes. At the SV40 promoter, we observed the expected localized interaction at the Spl sites; in addition, we found that DNA-bound Spl served to associate two or more DNA molecules. At a modified thymidine kinase promoter, we observed a localized interaction at each of two binding locations that were separated by $1.8 \mathrm{kbp}$; in addition, we noted a substantial fraction of DNA molecules in which the distant binding regions were joined by a DNA loop. As judged by studies with mutant Sp1 proteins, the distant interactions depended on the glutamine-rich regions of Sp1 required for transcriptional activation. We conclude that DNA-bound Sp1 can self-associate, bringing together distant DNA segments. From the correlation between DNA looping in vitro and synergistic activation of the modified thymidine kinase promoter shown previously in vivo, we suggest that Sp1 exerts its transcriptional synergism by a direct protein-protein association that loops the intervening DNA. Our experiments support the DNA-looping model for the function of transcriptional enhancers.
\end{abstract}

[Key Words: Spl protein; DNA looping; DNA binding; transcription]

Received December 26, 1990; revised version accepted January 23, 1991.

The controlled initiation of transcription in prokaryotes and eukaryotes depends on the action of regulatory proteins from sites that are too distant for a direct interaction with promoter-bound proteins on linear DNA. Three principal models have been proposed for positive regulation from distant (enhancer) sites (Dynan and Tjian 1985; Echols 1986; Ptashne 1986). In the first, the regulatory protein (or RNA polymerase) associates with the DNA at the enhancer site and then traverses the DNA to the promoter site (scanning model). In the second, the enhancer-binding protein initiates a change in DNA structure that is propagated from the enhancer to the promoter, thereby activating transcription (structural transmission model). In the third, the enhancerbound regulatory protein activates transcription by a direct protein-protein interaction with RNA polymerase at the promoter for other proteins that contact polymerase) (DNA-looping or nucleoprotein model).

DNA looping is currently favored as the most likely mechanism for distant regulatory interactions. The interaction between DNA-bound proteins has been firmly established as the central structural feature for regulated

${ }^{3}$ Present address: Wellcome CRC Institute, University of Cambridge, Cambridge CB2 1QR, UK.
DNA replication and site-specific recombination (Echols 1986; Gellert and Nash 1987; Landy 1989; Echols 1990). For multioperator prokaryotic regulation, DNA looping was proposed initially to explain the interaction of transcription regulators bound to spatially separated DNA sites (Dunn et al. 1984: Majumdar and Adhya 1984). More recently, a looping interaction between homologous regulatory proteins has been visualized directly by electron microscopy /Griffith et al. 1986; Krämer et al. 1987; Amouyal et al. 1989; Mandal et al. 1990). Recent biological and biochemical experiments with mutant repressors have correlated DNA-looping interactions with negative regulation in vivo in the gal and lac operons (Mandal et al. 1990; Oehler et al. 1990). For the prokaryotic enhancer of the $g \ln A$ gene, the DNA-looping model for positive regulation has been verified directly by the observation of the predicted heterologous interaction between enhancer-bound $\mathrm{NtrC}$ regulator protein and RNA polymerase at the promoter (Su et al. 1990).

For eukaryotic transcription systems, there has been published so far only limited, mainly indirect evidence for DNA looping. Recent work has shown that an enhancer site can stimulate transcription at a promoter site on a separate DNA molecule if the two sites are closely associated by DNA catenation (Dunaway and Dröge 


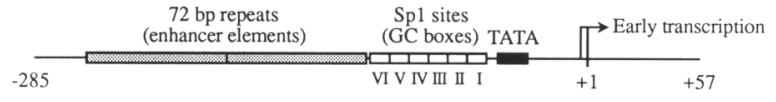

Figure 1. SV40 early promoter. The diagram is a schematic scale drawing of the restriction fragment used for the experiments. There are six Spl-binding sites (GC boxes) near the middle of the DNA fragment, between the upstream enhancer regions and the TATA site adjacent to the start point for early transcription.

1989) or protein-mediated tethering (Müller et al. 1989). In addition, a looping interaction between homologous proteins has been visualized by electron microscopy for the progesterone receptor (Theveny et al. 1987). We describe here work with the Sp1 transcriptional activator that correlates in vivo activation of transcription with DNA looping in vitro.

The Spl protein activates a specific subset of promoters transcribed by RNA polymerase II in vertebrates (Dynan and Tjian 1983; Jones et al. 1985, 1986; Dynan et al. 1986; Kadonaga et al. 1986; Mitchell and Tjian 1989). Spl binds to GGGGCGGGGC and closely related sequences, termed GC boxes (Letovsky and Dynan 1989; Mitchell and Tjian 1989). Transcriptional regulation by Spl depends on three zinc finger structures responsible for DNA binding and at least one of two glutamine-rich regions that are required for transcriptional function ("activation motifs") (Courey and Tiian 1988). Transcriptional activation by $\mathrm{Spl}$ has been defined most extensively for the SV40 early promoter and for the thymidine kinase (TK) promoter from herpes simplex virus (HSV). The region upstream of the SV40 promoter contains six GC boxes (Dynan and Tjian 1983; Kadonaga et al. 1986); the TK promoter carries two Spl-binding sites, a strong site (II) and a weaker site (I) (McKnight et al. 1984; Jones et al. 1985). The capacity of Spl to activate from distant sites has been demonstrated by the insertion of six GC boxes $\sim 1.8 \mathrm{~kb}$ downstream from the TK gene (TK-GC6 construction) (Courey et al. 1989). The downstreambinding region activates transcription even in the absence of the upstream-binding site; when both upstream and downstream sites were present, a much larger than additive effect was observed ("synergistic activation") (Courey et al. 1989). This synergistic interaction between the proximal- and distal-binding sites for Spl could be explained by the self-association of DNA-bound Spl to generate a highly active transcription complex.

In the work reported here, we have used electron microscopy to study the interaction of Spl protein with its specific binding sites and examine the ability of DNAbound Sp1 molecules to carry out protein-protein interactions. We have found that Sp1 can self-associate, joining distant DNA segments. The self-association reaction was observed only if Spl contained the glutamine-rich regions required for transcriptional activation. These experiments correlate synergistic activation of transcription in vivo with the direct demonstration of DNA looping in vitro. Another investigation with Spl has also demonstrated DNA looping and has focused on the higher-order structure of $\mathrm{Spl}$ (tetramer, octamer, dodecamer) at a self-association site (Mastrangelo et al. 1991).

\section{Results}

DNA-protein complexes by $S p 1$ at the $S V 40$ promoter

By using electron microscopy, we have studied the interaction of $\mathrm{Sp} 1$ protein with its specific binding sites

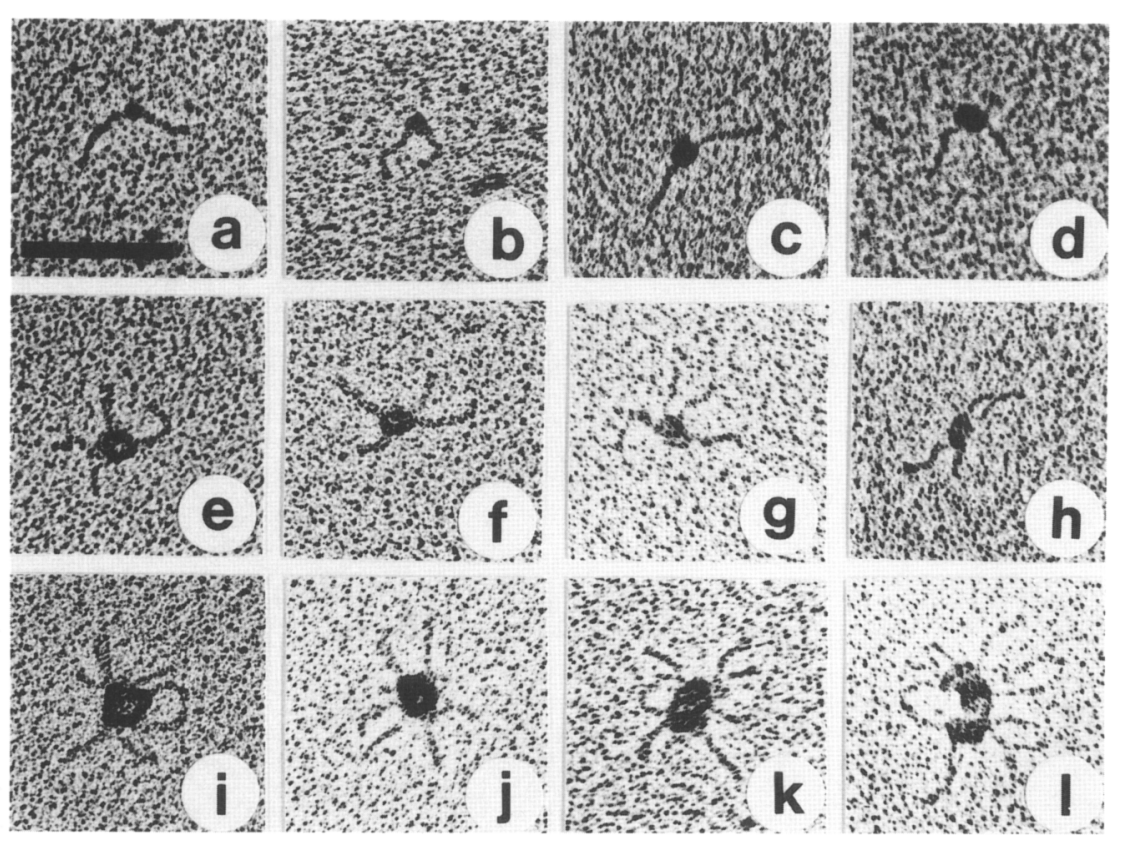

Figure 2. Interaction of Spl protein with SV40 DNA. The Sp1 was the wild-type protein purified from HeLa cells. The DNA was the SV40 fragment shown in Fig. 1. (ad) Simple complexes: Spl molecules bound to GC boxes in the DNA fragment. $(e-h)$ Double complexes: two DNA molecules associated by $\mathrm{Spl}$ to form X-shaped complexes. (i-l) Multiple complexes: three or more DNA molecules associated by $\mathrm{Sp} 1$ to form more complicated structures. Bar, 0.1 $\mu \mathrm{m}$. 
and probed the ability of DNA-bound Sp1 molecules to interact with each other. We initiated our work with the well-characterized SV40 early promoter. Purified Spl was added to an SV40 DNA fragment ( $342 \mathrm{bp}$ ) carrying the six GC boxes (Fig. 1). For wild-type Spl protein, $\sim 80 \%$ of the DNA molecules carried bound Spl (Fig. 2a-d; "simple complexes" in Table 1, column 21. To demonstrate the specificity of the interaction, we determined the position of the Spl complexes on the DNA by measuring the "tail" lengths of DNA from the free ends to the DNA-protein complex. These measurements mapped the Spl complexes to a region of $\sim 60 \mathrm{bp}$ congruent with the location of the GC boxes shown in Figure 1 (data not shown). We observed a distribution in the size of the DNA-protein complexes (Fig. 2a-d). Based on a comparison with RNA polymerase, we estimate that the smallest complexes carried one Sp1 molecule and the largest complexes carried four. Most of the structures appeared to have one or two Spl monomers (an estimated $20 \%$ with one, $50 \%$ with two, and $30 \%$ with three or four).

In the binding reaction with wild-type Spl, we observed protein-DNA complexes in which two DNA molecules were joined at the Spl-binding sites (Fig. 2e$h_{\text {; }}$ "double complexes" in Table 1, column 3). We also observed rarer instances in which more than two DNA molecules were joined (Fig. 2i-l; "multiple complexes" in Table 1, column 4). The joining of two or more DNA molecules at the $\mathrm{Spl-binding} \mathrm{site} \mathrm{was} \mathrm{a} \mathrm{relatively} \mathrm{fre-}$ quent event. For example, $10 \%$ of the DNA molecules

Table 1. DNA-protein complexes formed with SV4O DNA by wild-type and mutant Sp1 proteins

\begin{tabular}{lllll}
\hline & \multicolumn{3}{c}{ Percent of total observed structures as } \\
\cline { 2 - 5 } Spl structure & free & simple double & multiple \\
(Gln-rich/zinc finger) & DNA & complex & complex \\
complex
\end{tabular}

(Simple complex) Sp1 binding to one DNA molecule. (Double complex) The X-shaped structures formed by Sp1-mediated joining of two DNA molecules. (Multiple complex) The more complicated structures formed by Spl-mediated joining of three or more DNA molecules. The simple complexes reported for $168 \mathrm{C}$ presumably carry multiple $168 \mathrm{C}$ protein molecules, because a single $168 \mathrm{C}$ is too small to be visualized on DNA (b168C is $18 \mathrm{kD}$, compared to $100 \mathrm{kD}$ (wild-type; wt) and $37 \mathrm{kD}$ (bC22E). (A and B) The two glutamine-rich activation domains; $(\mathrm{Zn})$ the zinc finger DNA-binding domain. The wild-type and $168 \mathrm{C}$ proteins were purified from HeLa cells, and bC22E and bl68C proteins were purified from $E$. coli. The DNA concentration was $20 \mathrm{nM}$; the concentration of Spl proteins was $80 \mathrm{nM}$ for the data in lines 1 and 2 and $40 \mathrm{~nm}$ for lines 3 and 4 . The total number of structures counted for each number was 400 . were observed as double complexes (two DNA molecules for each structure scored in Table 1). The double complexes and the multiple complexes contained a number of $\mathrm{Spl}$ molecules, as judged by their size (e.g., Fig. 2e-1); the multiple complexes carried more Spl than the double complexes carried. Thus, the $\mathrm{Spl}$ interactions that join DNA molecules presumably represent multiprotein association complexes. We conclude that DNAbound $\mathrm{Spl}$ can self-associate efficiently to join distant DNA segments. We have not observed such a DNA-joining reaction with the DNA-binding transcriptional regulators NtrC (Su et al. 1990) or GalR (W. Su and H. Echols, unpubl.).

We wanted to determine whether a correlation existed between the capacity of DNA-bound Spl to self-associate and the ability of the protein to activate transcription in vivo. For this purpose, we used mutants of Spl missing one or both of the glutamine-rich activation segments. We chose the Spl mutant $168 \mathrm{C}$ because of its binding-positive, activation-negative phenotype. Although this mutant protein lacks both glutamine-rich domains and thus is inactive in transcription activation, the $168 \mathrm{C}$ protein binds to the GC boxes as effectively as wild-type Sp1, as judged by DNase footprinting, affinity chromatography, and gel-shift assays (Kadonaga et al. 1988; J.J. MacDonald, S.P. Jackson, and R. Tjian, unpubl.). We observed that $168 \mathrm{C}$ failed to link DNA molecules by the self-association reaction (Table 1, line 2). To explore further the correlation between the glutamine-rich domains of $\mathrm{Spl}$ and the self-association of DNA-bound $\mathrm{Spl}$, we studied another mutant protein, $\mathrm{C} 22 \mathrm{E}$, which carries only one glutamine-rich region (Table 1, line 3). This Spl mutant is less than half the size of wild-type Sp1, containing only the segment of $\mathrm{Spl}$ found in $168 \mathrm{C}$ plus a single glutamine-rich domain; nevertheless, C22E is proficient for activation of transcription (Courey and Tjian 1988). Because the C22E protein was produced in bacteria (designated by bC22E in Table 1), this mutant was compared with the $168 \mathrm{C}$ mutant produced in bacteria (b168C) (Table 1, line 4). For this second pair of Spl proteins, the capacity to join DNA molecules also correlated with the presence of a glutaminerich transcriptional activation region.

In the data reported in Table 1, we observed fewer single Spl-DNA complexes for the $168 \mathrm{C}$ mutant than for wild-type Spl or the C22E mutant. This result was expected because of the difficulty in visualizing the very small $168 \mathrm{C}$ protein $\{18$ vs. $100 \mathrm{kD}$ for wild-type Spl). On the basis of our previous experience with DNA-binding proteins, a protein of $<50 \mathrm{kD}$ cannot be observed reliably by the polylysine technique for DNA-protein complexes. For example, by direct observation we can score only about half of the DNA-protein complexes for the transcription factor TFIID (40 kD) (the rest can be detected by a sharp DNA bend at the binding site) (W. Su and $\mathrm{H}$. Echols, unpubl.). For the $168 \mathrm{C}$ mutant protein, we expected to detect only DNA-protein complexes carrying three or four monomers (the minority class for wild type). The ability to observe joined DNA molecules does not depend on visualizing the DNA-protein complex. 
Even ignoring the underscoring for $168 \mathrm{C}$, the observed lower number of single complexes clearly cannot account for the vanishing class of joined DNA molecules; $\sim 16 \%$ of total DNA molecules are joined for both wild type and C22E. From the data of Table 1, we conclude that the ability of $\mathrm{Sp} 1$ to associate distant DNA segments probably depends on the glutamine-rich regions of the protein required for transcriptional activation.

\section{DNA looping by Sp1 at the thymidine kinase promoter}

The experiments with the SV40 promoter demonstrated the ability of DNA-bound $\mathrm{Spl}$ to self-associate, joining distant segments of DNA. These results suggested that a similar self-association by Sp1 might explain the synergistic interaction between proximal- and distal-binding sites observed for transcriptional activation of the TKGC6 promoter in vivo (Fig. 3) (Courey et al. 1989). For this communication between distant binding sites on the same DNA molecule, we would expect to observe DNA looping between Spl bound to the upstream and downstream sites (Fig. 3).

We looked for the DNA-looping interaction by electron microscopy of a DNA segment with Spl-binding sites close to each end, so that the looping interaction would be readily observable as a circular DNA molecule (Fig. 3). Examples of the DNA-protein complexes are shown in Figure 4, and the quantitative data are presented in Table 2. DNA-protein complexes were found with both single-site (Fig. 4a) and double-site binding (Fig. 4b,c). The binding reactions can be presumed to be
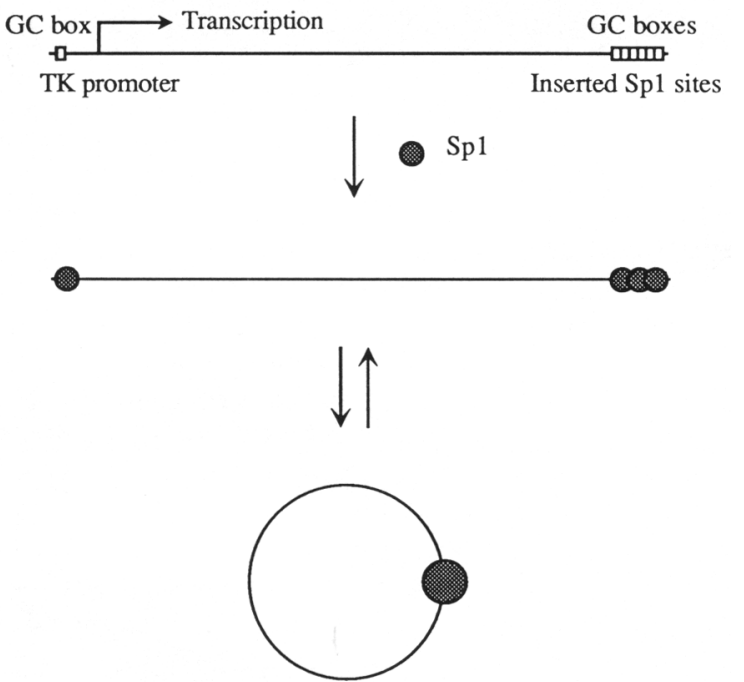

Figure 3. Possible Sp1-DNA complexes at the TK promoter. (Top) The engineered TK promoter. The GC boxes are enlarged for clarity; the weak Sp1-binding site in the TK promoter is not shown. Transcription starts $\sim 100$ bp downstream from the upstream GC box. The six GC boxes downstream are three repeats of sites III and IV in SV40. The distance between the upstream and downstream GC boxes is $\sim 1.8 \mathrm{kbp}$. site specific because no nonspecific end-binding reactions were seen with the SV40 DNA; moreover, binding near both ends was observed only with the double-site DNA. Most importantly, we observed a substantial number of circular DNA molecules; the percentage of loops was higher than that for double-bound linear molecules (Fig. 4d-k; Table 2, line 1). These data suggest that the majority of DNA molecules with both binding sites occupied have formed DNA loops by self-association of $\mathrm{Spl}$. Formation of the looped DNA molecules depended on the presence of both upstream and downstream Splbinding sites (Table 2, lines 2 and 3). Thus, we conclude that Sp1 bound to distant DNA sites can interact by a DNA-looping interaction that correlates with the capacity of $\mathrm{Spl}$ for synergistic activation of transcription in vivo.

We also compared the DNA-looping interaction for wild-type Spl and the $168 \mathrm{C}$ mutant lacking the glutamine-rich activation domains. The mutant Spl failed to execute the DNA-looping interaction (Table 3). The experiments with the $168 \mathrm{C}$ mutant have the same technical limitation as those of Table 1-the difficulty in visualizing the small $168 \mathrm{C}$ protein by electron microscopy. However, the visualization of looped DNA molecules does not depend on detecting the bound protein; no loops were found for $168 \mathrm{C}$. Thus, the data of Table 3 (together with Table 1) provide a strong indication that DNA looping depends on protein-protein interaction specified by the region of $\mathrm{Sp} 1$ required for transcription activation.

\section{Discussion}

\section{DNA-looping interaction by $S p 1$ protein}

By using electron microscopy, we have demonstrated that DNA-bound Sp1 molecules can self-associate to join distant DNA segments. For the modified TK promoter carrying upstream- and downstream-binding sites, the association of DNA-bound Spl loops the intervening DNA. In vivo, a functional interaction between the upstream- and downstream-binding sites results in a very large synergistic activation of transcription (Courey et al. 1989). From the correlation between transcriptional activation in vivo and DNA looping in vitro, we propose that $\mathrm{Sp} 1$ exerts its transcriptional synergism by a direct protein-protein association of $\mathrm{Sp} 1$ bound to the upstream and downstream sites. A recent study with E2activator protein of bovine papillomavirus has also correlated DNA looping with transcription activation (Knight et al. 1991).

The ability of Spl to associate distant DNA sites depends on the presence of at least one of the glutaminerich domains of the protein required for activation of transcription. Thus, we believe that the DNA-looping interaction between homologous $\mathrm{Spl}$ proteins is probably functionally related to the presumed heterologous interaction of Spl with the transcription complex at the promoter (Mitchell and Tjian 1989; Pugh and Tjian 
Su et al.

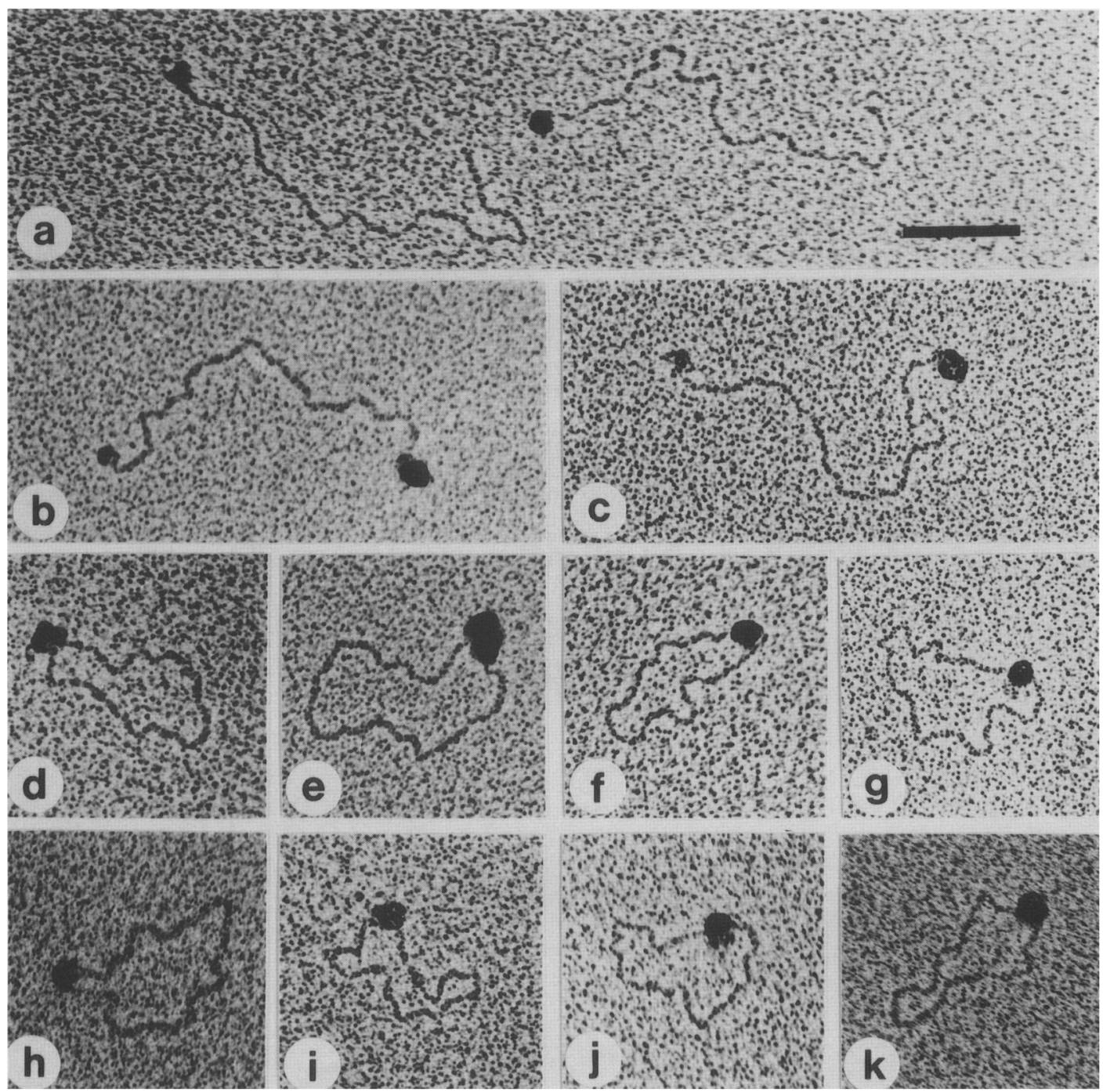

Figure 4. Interaction of $\mathrm{Spl}$ protein with the engineered $\mathrm{TK}$ promoter. The $\mathrm{Sp} 1$ was the wild-type protein purified from HeLa cells. The DNA was the fragment shown in Fig. 3. (a) Spl binding to either upstream or downstream sites. $(b-c)$ Spl binding to both upstream and downstream sites. $(d-k)$ The upstream-bound Spl and the downstream-bound Sp1 associated to loop the intervening DNA. Bar, $0.1 \mu \mathrm{m}$.

1990). Although this critical heterologous protein-protein interaction has not yet been demonstrated in vitro, the capacity of $\mathrm{Sp} 1$ to mediate DNA-looping interactions supports the general validity of the DNA-looping model for the function of transcriptional enhancers. For the prokaryotic transcriptional enhancer of the $g \ln A$ promoter, we have visualized the heterologous DNA-looping interaction between the enhancer-bound $\mathrm{NtrC}$ activator protein and RNA polymerase at the promoter (Su et al. 1990).

\section{Role of multiple regulatory interactions in DNA transactions}

Recent experimental work has indicated strongly that a fundamentally similar mechanism regulates initiation of transcription, DNA replication, and site-specific recom- bination (Echols 1986, 1990). The controlled activity of specific DNA sites usually depends on the multiple interaction of DNA-bound proteins, often located at distant regulatory sites, bending or winding the intervening DNA. These specialized nucleoprotein structures (often called "snups") provide at least two advantages over a single regulatory interaction: (1) more precise localization of the initiation site for the DNA transaction; and (2) more broadly and tightly controlled activity through multiple functional or temporal inputs.

The activity of specialized nucleoprotein structures is generally characterized by multiple interactions between homologous regulatory proteins of the type that we have described here for Spl. In addition, there are heterologous interactions with other regulatory proteins and the catalytic machinery at the initiation site (Echols 1986, 1990; Adhya 1989; Johnson and McKnight 1989; 
Table 2. DNA-protein complexes formed with wild-type Sp1 and separated binding regions

\begin{tabular}{|c|c|c|c|c|c|c|}
\hline \multirow{2}{*}{\multicolumn{2}{|c|}{ DNA fragment }} & \multicolumn{5}{|c|}{ Number (and percent) of total observed structures as } \\
\hline & & \multirow[t]{2}{*}{ free DNA } & \multirow{2}{*}{$\begin{array}{l}\text { up or } \\
\text { downstream }\end{array}$} & \multirow{2}{*}{$\begin{array}{l}\text { up and } \\
\text { downstream }\end{array}$} & \multirow[t]{2}{*}{ loop } & \multirow{2}{*}{$\begin{array}{l}\text { multiple } \\
\text { complex } \\
\\
\end{array}$} \\
\hline Spl sites & structure & & & & & \\
\hline Both & ar & $123(31)$ & $225(56)$ & $10(2.5)$ & $17(4)$ & $25(6)$ \\
\hline Downstream & 工 & $265(66)$ & $123(31)$ & $0\langle 0\rangle$ & $0(0)$ & $12(3)$ \\
\hline Upstream & or & $321(80)$ & $73(18)$ & $0\langle 0\rangle$ & $1(0.2)$ & $5(1)$ \\
\hline
\end{tabular}

(Up or downstream) The DNA-protein complexes with Sp1 bound to the site/s) at one end. (Up and downstream) The complexes with Spl bound to the sites at both ends. (Multiple complex) The complexes containing two or more DNA molecules. Spl was the wild-type protein purified from HeLa cells. The upstream Sp1 site is the one in the normal TK promoter; the downstream sites are the inserted GC boxes from SV40. The DNA fragment containing both sites was isolated from the plasmid - 105tkCAT15; the fragment containing only the downstream site was isolated from tkCAT15; the fragment containing only the upstream site was isolated from - 105tkCAT (Courey et al. 1989). The concentration of the DNA fragments was $0.4 \mathrm{nM}$; the concentration of Spl was $3.2 \mathrm{nM}$. The total number of structures counted for each number was 400 .

Mitchell and Tjian 1989|. For eukaryotic transcription, the multiple interactions probably serve both to increase occupancy of the regulatory sites and to provide multiple inputs into the RNA polymerase complex at the promoter. A summation of functional interaction domains (positive or negative) at the promoter might be the key to a transcription switch.

\section{Materials and methods}

DNA

SV40 DNA with the early promoter region was isolated from plasmid pUCSVCAT (Courey and Tiian 1988). Digestion of the plasmid DNA by HindIII released the 342-bp fragment used for the experiments. The pure DNA fragment was isolated after electrophoresis in a $1.5 \%$ agarose gel. TK promoter fragments were isolated from plasmids - 105tkCAT15, tkCAT15, and - 105tkCAT (Courey et al. 1989). The - 105tkCAT15 DNA contains both the upstream GC box and downstream GC boxes; tkCAT15 contains only the downstream GC boxes; and - 105tkCAT contains only the upstream site. Each of the three fragments was purified by gel electrophoresis after digestion of the plasmid DNA by SphI and SacI.

Proteins

Wild-type $\mathrm{Sp} 1$ protein and the $168 \mathrm{C}$ mutant were purified from a vaccinia virus-HeLa cell expression system (Jackson et al. 1990). The b168C and bC22E proteins were purified from an Escherichia coli expression system (Kadonaga et al. 1988). The bC22E protein is derived from a construction similar to the previously characterized 440C $\Delta$ int 112 (Courey and Tjian 1988); the C22E protein is essentially $168 \mathrm{C}$ plus a single glutaminerich activation domain.

\section{Electron microscopy}

DNA-binding reactions $(10 \mu \mathrm{l})$ contained $25 \mathrm{~mm}$ Tris- $\mathrm{HCl}(\mathrm{pH}$ 7.8), $50 \mathrm{~mm} \mathrm{KCl}, 10 \mathrm{~mm} \mathrm{MgCl}_{2}, 0.5 \mathrm{~mm}$ EDTA, $0.5 \mathrm{~mm}$ DTT, and $10 \%$ glycerol. For SV40 DNA, the reactions contained 20 nM DNA and $40 \mathrm{nM} \mathrm{Spl} \mathrm{(monomer} \mathrm{concentration).} \mathrm{The} \mathrm{protein}$ concentration was estimated by the staining intensity of Spl compared to reference proteins, following acrylamide gel electrophoresis. The reaction mixtures were incubated at room temperature for $40 \mathrm{~min}$. The samples were diluted 10 times and loaded on grids within $5 \mathrm{sec}$. For TK DNA, the reactions contained $0.4 \mathrm{nM}$ DNA and $3.2 \mathrm{nM} \mathrm{Spl}$. The reaction mixtures were incubated at room temperature for $40 \mathrm{~min}$ and loaded onto grids without dilution. No fixation was used. Electron microscopy was carried out by the polylysine technique (Williams 1977). Grids were rotary-shadowed with tungsten.

\section{Acknowledgments}

We thank Albert Courey for the TK promoter constructions,

Table 3. DNA-protein complexes formed with wild-type and mutant Sp1 and distant binding regions

\begin{tabular}{|c|c|c|c|c|c|}
\hline \multirow[b]{2}{*}{ Spl structure } & \multicolumn{5}{|c|}{ Number (and percent) of total observed structures as } \\
\hline & free DNA & $\begin{array}{l}\text { up or } \\
\text { downstream }\end{array}$ & $\begin{array}{l}\text { up and } \\
\text { downstream }\end{array}$ & loop & $\begin{array}{l}\text { multiple } \\
\text { complex }\end{array}$ \\
\hline $\begin{array}{lll}- & \\
\text { A } & \text { B } & \mathrm{Zn}\end{array}$ & & & 0 & & $\overline{-}$ \\
\hline WT $(-\square-0-1$ & $161(40)$ & $177(44)$ & $11(3)$ & $29(7)$ & $22(6)$ \\
\hline $168 \mathrm{C}(-n-)$ & $364(91)$ & $33|8\rangle$ & $2(0.5\rangle$ & $0(0)$ & $1(0.2)$ \\
\hline
\end{tabular}

The DNA fragment carried both upstream and downstream sites $(-105$ tkCAT15). The terms used are explained in the footnotes to Tables 1 and 2 . As noted for Table 1 , the small size of the $168 \mathrm{C}$ protein presumably leads to an underestimate of DNA-bound protein for the up- or downstream and up- and downstream complexes. The concentration of the DNA fragments was $0.4 \mathrm{nM}$; the concentration of $\mathrm{Spl}$ alleles was $3.2 \mathrm{~nm}$. The wild-type and 168C proteins were purified from HeLa cells. The total number of structures counted for each number was 400 . 
Rick Eisner for editorial assistance, and Frank Pugh for advice on the manuscript. This work was supported in part by grants from the National Institutes of Health to R.T. and H.E. S.J. was a recipient of a Senior Fellowship from the Leukemia Society of America.

The publication costs of this article were defrayed in part by payment of page charges. This article must therefore be hereby marked "advertisement" in accordance with 18 USC section 1734 solely to indicate this fact.

\section{References}

Adhya, S. 1989. Multipartite genetic control elements: Communication by DNA loop. Annu. Rev. Gen. 23: 227-250.

Amouyal, M., L. Mortensen, H. Buc, and K. Hammer. 1989. Single and double loop formation when $d e o R$ repressor binds to its natural operator sites. Cell 58: 545-551.

Courey, A.J. and R. Tjian. 1988. Analysis of $\mathrm{Spl}$ in vivo reveals multiple transcriptional domains, including a novel glutamine-rich activation motif. Cell 55: 887-898.

Courey, A.J., D.A. Holtzman, S.P. Jackson, and R. Tjian. 1989. Synergistic activation by the glutamine-rich domains of human transcription factor Spl. Cell 59: 827-836.

Dunaway, M. and P. Dröge. 1989. Transactivation of the Xenopus rRNA gene promoter by its enhancer. Nature 341: 657659.

Dunn, T.M., S. Hahn, S. Ogden, and R.F. Schleif. 1984. An operator at -280 base pairs that is required for repression of araBAD operon promoter: Addition of DNA helical turns between the operator and promoter cyclically hinders repression. Proc. Natl. Acad. Sci. 81: 5017-5020.

Dynan, W.S. and R. Tjian. 1983. Isolation of transcription factors that discriminate between different promoters recognized by RNA polymerase II. Cell 32: 669-680.

1985. Control of eukaryotic mRNA synthesis by sequence-specific DNA binding proteins. Nature 316: 774 778.

Dynan, W.S., S. Sazer, R. Tjian, and R.T. Schimke. 1986. Transcription factor $S p l$ recognizes a DNA sequence in the mouse dihydrofolate reductase promoter. Nature 319: 246248.

Echols, H. 1986. Multiple DNA-protein interactions governing high-precision DNA transactions. Science 233: 1050-1056.

1990. Nucleoprotein structures initiating DNA replication, transcription, and site-specific recombination. J. Biol. Chem. 265: 14697-14700.

Gellert, M. and H. Nash. 1987. Communication between segments of DNA during site-specific recombination. Nature 325: 401-404.

Griffith, I., A. Hochschild, and M. Ptashne. 1986. DNA loops induced by cooperative binding of $\lambda$ repressor. Nature 322: $750-752$

Jackson, S.P., J.J. MacDonald, S. Lees-Miller, and R. Tjian. 1990. GC box binding induces phosphorylation of SpI by a DNAdependent protein kinase. Cell 63: 155-165.

Johnson, P.F. and S.L. McKnight. 1989. Eukaryotic transcriptional regulatory proteins. Annu. Rev. Biochem. 58: 799839.

Jones, K.A., K.R. Yamamoto, and R. Tijian. 1985. Two distinct transcription factors bind to the HSV thymidine kinase promoter in vitro. Cell 42: 559-572.

Jones, K.A., J.T. Kadonaga, P.A. Luciw, and R. Tjian. 1986. Activation of the AIDS retrovirus promoter by the cellular transcription factor, Spl. Science 232: 755-759.

Kadonaga, J.T., K.A. Jones, and R. Tjian. 1986. Promoter-specific activation of RNA polymerase II transcription by Spl. Trends Biochem. 11: 20-23.

Kadonaga, J.T., A.J. Courey, J. Ladika, and R. Tjian. 1988. Distinct regions of Spl modulate DNA binding and transcriptional activation. Science 242: 1566-15670.

Knight, J., R. Li, and M. Botchan. 1991. The activation domain of the bovine Papillomavirus E2 protein mediates association of DNA bound dimers to form DNA loops. Proc. Natl. Acad. Sci. (in press)

Krämer, H., M. Niemöller, M. Amouyal, B. Revet, B. von Wilcken-Bergmann, and B. Müller-Hill. 1987. lac repressor forms loops with linear DNA carrying two suitably spaced lac operators. EMBO I. 6: 1481-1491.

Landy, A. 1989. Dynamic, structural and regulatory aspects of $\lambda$ site-specific recombination. Annu. Rev. Biochem. 58: 913 950.

Letovsky, J. and W. Dynan. 1989. Measurement of the binding of transcription factor Spl to a single GC box recognition sequence. Nucleic Acids Res. 17: 2639-2652.

Majumdar, A. and S. Adhya. 1984. Demonstration of two operator elements in gal: In vitro repressor binding studies. Proc. Natl. Acad. Sci. 81: 6100-6104.

Mandal, N., W. Su, R. Haber, S. Adhya, and H. Echols. 1990. DNA looping in cellular repression of transcription of the galactose operon. Genes \& Dev. 4: 410-418.

Mastrangelo, I.A., A.J. Courey, J.S. Wall, S.P. Jackson, and P.V.C. Hough. 1991. DNA looping and Spl multimer links: A mechanism for transcriptional synergism and enhancement. Proc. Natl. Acad. Sci. (in press).

McKnight, S.L., R.C. Kingsbury, A. Spence, and M. Smith. 1984. The distal transcription signals of the Herpesvirus tk gene share a common hexanucleotide control sequence. Cell 37: 253-262.

Mitchell, P.J. and R. Tjian. 1989. Transcriptional regulation in mammalian cells by sequence-specific DNA-binding proteins. Science 245: 371-378.

Müller, H.-P., J.M. Sogo, and W. Schaffner. 1989. An enhancer stimulates transcription in trans when attached to the promoter via a protein bridge. Cell 58: $767-777$.

Oehler, S., E.R. Eismann, H. Krämer, and B. Müller-Hill. 1990. The three operators of the lac operon cooperate in repression. EMBO I. 9: 973-979.

Ptashne, M. 1986. Gene regulation by proteins acting nearby and at a distance. Nature 322: 697-701.

Pugh, B.F. and R. Tjian. 1990. Mechanism for transcriptional activation by SP1: Evidence for coactivators. Cell 61: 11871197.

Su, W., S. Porter, S. Kustu, and H. Echols. 1990. DNA-looping and enhancer activity: Association between DNA-bound NtrC activator and RNA polymerase at the bacterial glnA promoter. Proc. Natl. Acad. Sci. 87: 5504-5508.

Theveny, B., A. Bailly, C. Rauch, M. Rauch, E. Delain, and E. Milgrom. 1987. Association of DNA-bound progesterone receptors. Nature 329: 79-81.

Williams, R. 1977. Use of polylysine for adsorption of nucleic acids and enzymes to electron microscope specimen films. Proc. Nat1. Acad. Sci. 74: 2311-2315. 


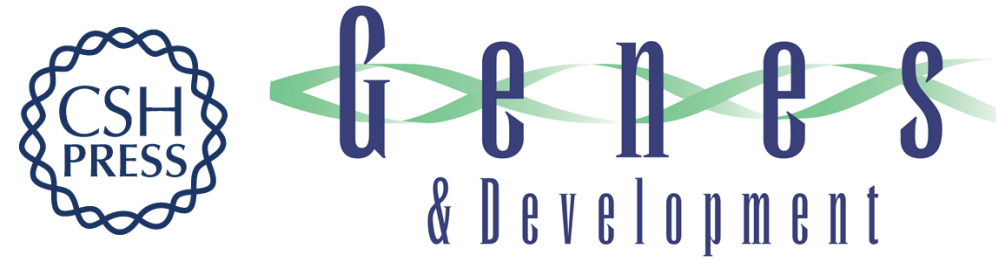

\section{DNA looping between sites for transcriptional activation: self-association of DNA-bound Sp1.}

W Su, S Jackson, R Tjian, et al.

Genes Dev. 1991, 5:

Access the most recent version at doi:10.1101/gad.5.5.820

References This article cites 33 articles, 10 of which can be accessed free at:

http://genesdev.cshlp.org/content/5/5/820.full.html\#ref-list-1

License

Email Alerting Receive free email alerts when new articles cite this article - sign up in the box at the top Service right corner of the article or click here.

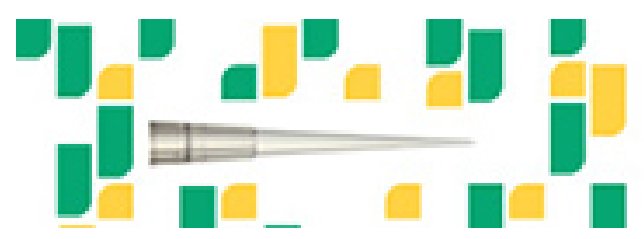

Focused on your science.

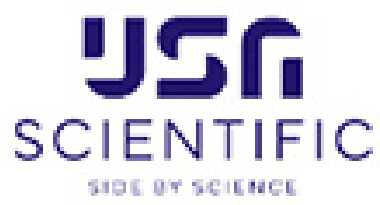

Copyright (c) Cold Spring Harbor Laboratory Press 